GYNECOLOGIC ONCOLOGY 14, 382-391 (1982)

\title{
Confirmation of Metastases by Fine Needle Aspiration Biopsy in Patients with Gynecologic Malignancies
}

\author{
Andrew Flint, M.D., ${ }^{*}, 1$ Kathleen Terhart, C.T. (ASCP), $\dagger$ Tariq M. Murad, \\ M.D., Ph.D., $\dagger$ and Peyton T. TAylor, M.D. $\ddagger$ \\ ${ }^{*}$ Department of Pathology, University of Michigan, Ann Arbor, Michigan 48109; $\dagger$ University of \\ Alabama, Birmingham, Alabama 35294; and $\ddagger$ Department of Obstetrics and Gynecology, \\ University of Virginia, Charlottesville, Virginia 22904
}

Received November 24, 1981

\begin{abstract}
Fine needle aspirations (FNA) were performed on 48 patients treated for gynecologic malignancies and suspected of having recurrence of their disease. The suspected sites of metastases were peripheral lymph nodes (38 patients) and the retroperitoneal region (10 patients). Metastatic tumors were detected in 22 out of the 48 patients (45\%) by FNA, with 9 patients having additional confirmation by excisional biopsies. Of the remaining patients, 9 had unsatisfactory specimens, and 2 had falsc-negative results. The report emphasizes the efficacy of this procedure, especially when positive results are obtained. Open biopsy can be restricted to those patients with negative or unsatisfactory results and a high clinical suspicion of metastasis.
\end{abstract}

\section{INTRODUCTION}

The optimal treatment of patients with gynecologic malignancies requires an accurate assessment of the extent of their disease. The presence or absence of metastatic foci determines, in large part, the treatment modalities employed as well as the prognosis. Similarly, the detection of metastatic foci in patients who have already been treated influences subsequent therapy. Radiographic and lymphangiographic studies are often employed for this purpose. Suspicious lesions are customarily biopsied, a procedure which may require operative scheduling and general anesthesia.

Fine needle aspiration (FNA) of clinically suspicious peripheral lymph nodes in patients with malignant disease has been the subject of several earlier reports [1-4]. However, there have been relatively few reports which have dealt with the use of FNA in the detection of recurrent or metastatic gynecologic tumors $[5,6]$. In this report, we present our experience with the use of FNA in patients with gynecologic malignancies.

\section{MATERIALS AND METHODS}

The files of the division of cytology at the University of Alabama in Birmingham were searched for patients with gynecologic tumors who had undergone FNA.

\footnotetext{
' To whoin correspondence should be addressed.
} 
A total of 48 patients covering a 48 -month period were identified. Of this group, 22 patients had been trcated for cervical tumors (19 cases of squamous cell carcinoma and 3 cases of adenocarcinoma of the endocervix). A further 9 patients had been treated for endometrial malignancy ( 6 patients with adenocarcinoma, 2 patients with malignant mixed mullerian tumors, and 1 case of endolymphatic stromal myosis). An additional 9 patients were diagnosed as having ovarian adenocarcinoma while 2 others had vulvar squamous cell carcinoma. Finally, 6 patients had been treated for squamous cell carcinoma of the vagina (Table $1)$.

All patients were treated at the University of Alabama Hospitals and Clinics. Various treatment modalities were employed, including surgery, radiation, and chemotherapy. Recurrent or metastatic disease was manifested clinically either by peripheral lymph node enlargement (38 patients) or by symptomatology referrable to abdominal or retroperitoneal masses (10 patients). Clinical follow-up was obtained by reviewing each patient's medical record. Twenty-one patients underwent an excisional biopsy of the suspicious area shortly following the FNA. Excisional biopsy was not performed in later cases as more experience was gained in both performing the aspirations as well as in interpreting the cytologic results. Each FNA specimen was independently reviewed by two of the authors (A.F., K.T.). The concurrent excisional biopsies were also reviewed and the histologic features were compared with the cytologic features of the aspirated material.

\section{Aspiration Techniques}

The aspiration samples were obtained by several faculty and staff members. The preferred instrument consisted of a disposable syringe fitted to a special handle to allow one-handed operation. This was not used for every case. A standard 22-gauge, thin-walled disposable needle was attached to the syringe for superficial lesions. For deep-seated lesions, a disposable, 22-gauge spinal needle was employed.

The skin overlying the site was cleansed with antiseptic and one hand was used to immobilize the lesion. Local anesthesia was used in the abdominal wall

TABLE 1

Sites of Primary Tumors and Suspected Metastases

\begin{tabular}{lcccccc}
\hline \multicolumn{1}{c}{ Primary tumor } & Inguinal & Femoral & Retroperitoneal & Pelvic & Supraclavicular & Total \\
\hline Cervix $^{a}$ & 12 & & 9 & & 1 & 22 \\
Endometrium $^{b}$ & 7 & & & & 2 & 9 \\
Ovary (adenocarcinoma) $_{\text {Vagina (squamous cell CA) }}$ & 8 & 1 & & 1 & 1 & 9 \\
Vulva (squamous cell CA) & 2 & & & & & 6 \\
$\quad$ Total & 33 & 1 & 9 & 1 & 4 & 48 \\
\hline
\end{tabular}

\footnotetext{
a Cervical tumors include 19 cases of squamous cell carcinoma and 3 cases of adenocarcinoma.

${ }^{b}$ Endometrial tumors include 6 cases of adenocarcinoma, 2 mixed mullerian tumors, and 1 case of endolymphatic stromal myosis.
} 
when transabdominal aspirates were performed. The needle was inserted into the mass and negative pressure was generated by retracting the plunger. The needle was moved back and forth several millimeters to take advantage of the cutting bevel of the needle. Negative pressure was released prior to removal of the needle from the mass. The aspirated material was usually contained within the needle and the aspirate was expressed onto clean frosted-glass slides, smeared out, and immediately fixed in alcohol.

\section{RESULTS}

Metastatic carcinoma was detccted in 22 out of 48 paticnts $(45 \%)$ by FNA. Nine patients of this group had also undergone an excisional biopsy of the same site. The excisional biopsy demonstrated similar metastatic disease in all nine cases. The tumor aspirates were usually highly cellular and the tumor cells were easily discernible from the background of lymphoid tissue. Depending on the degree of differentiation of the tumor, a specific diagnosis could be rendered. Poorly differentiated squamous cell carcinoma often forms nests of fairly cohesive cells which could easily be distinguished from the background of normal cellular elcments (Fig. 1). Well-differentiated squamous cell carcinoma, on the other hand, is often represented by single cells and syncytia. The single cells were often ovoid or polyhedral, having sharp borders and centrally located hyperchromatic nuclei (Fig. 2). The nuclear envelope was often indented or crenated

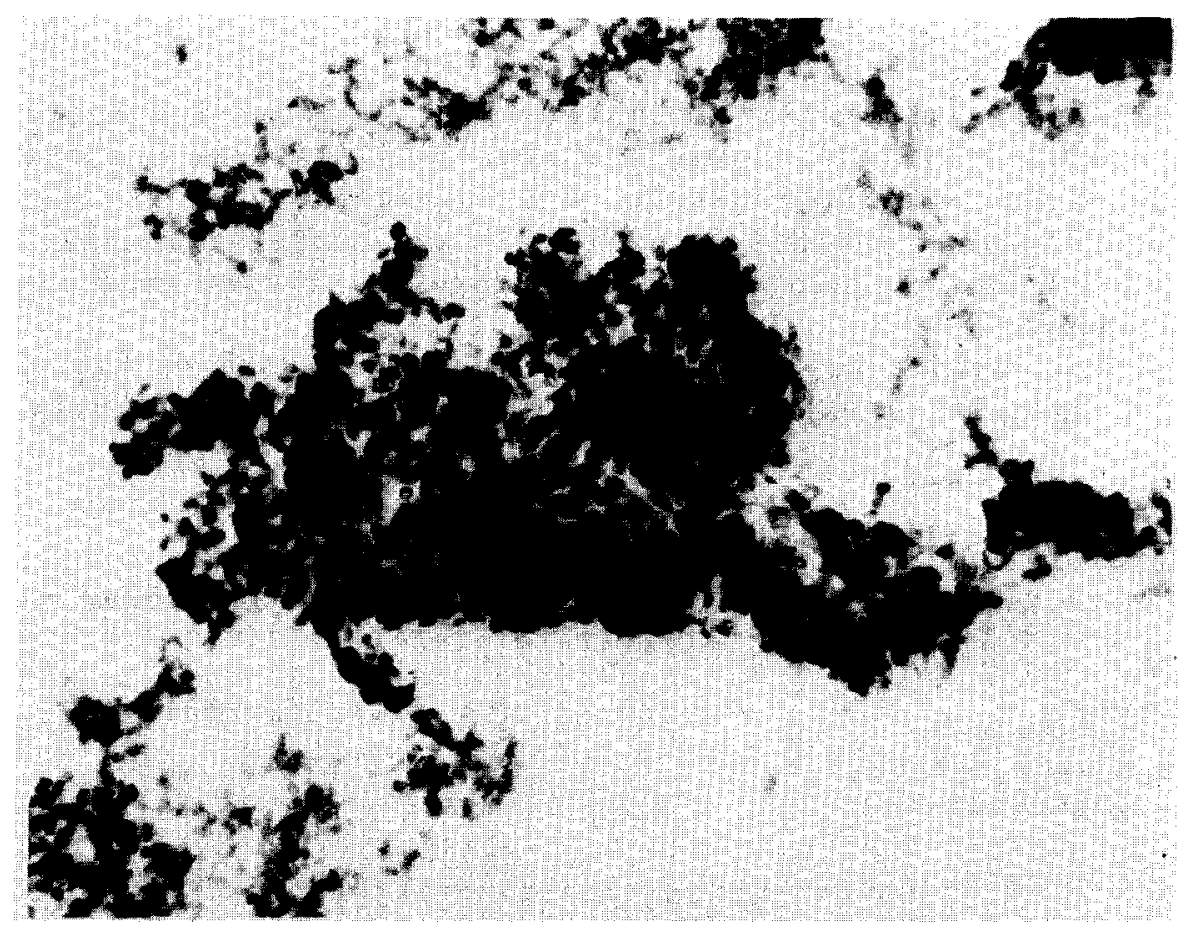

FIG. 1. Squamous cell carcinoma. Note the enlarged hyperchromatic nuclei with irregular chromatin. Both individual tumor cells as well as small syncytia are present (Papanicolau stain, $100 \times$ ). 


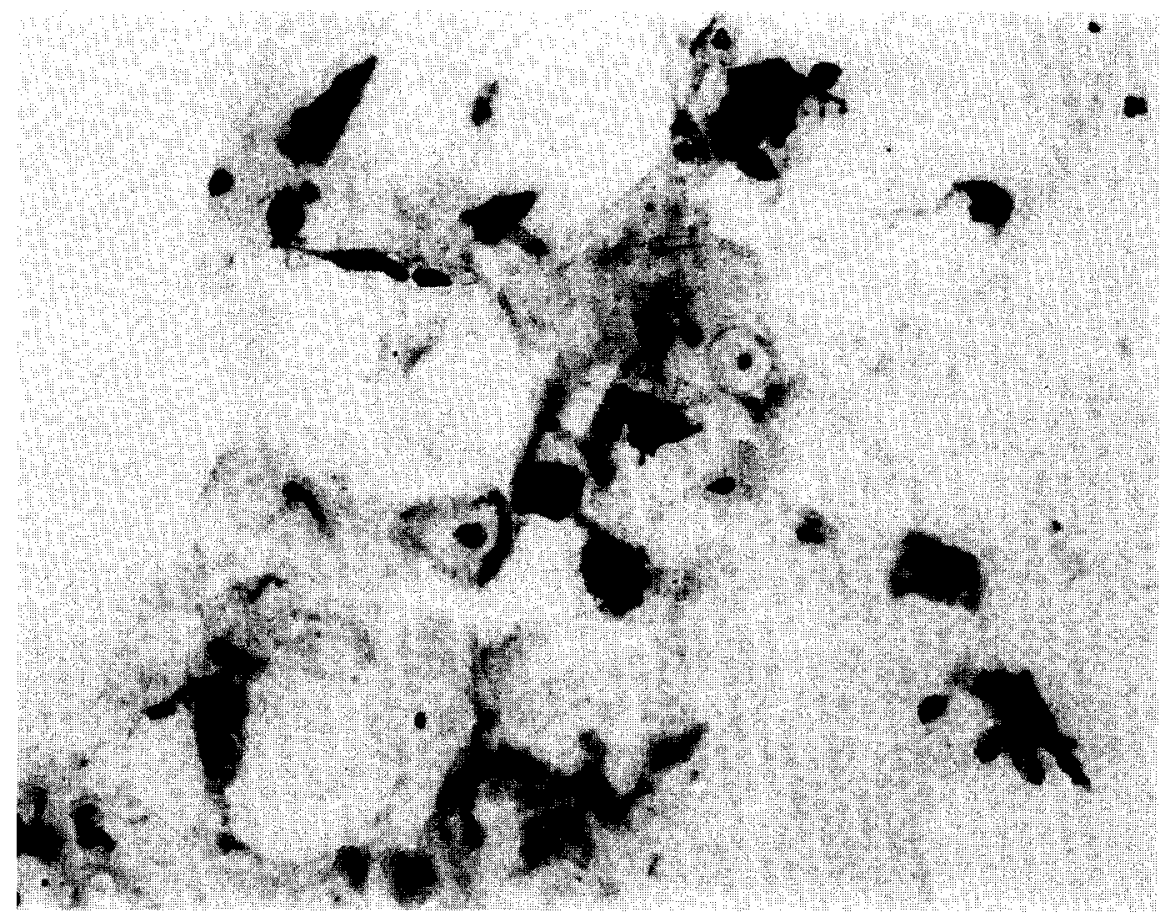

FIG. 2. Squamous cell carcinoma. Single cells with irregular hyperchromatic nuclei (Papanicolau stain, $160 \times)$.

and the cytoplasm was often thick and eosinophilic. Upon reviewing the vaginal biopsies, when available, similar cells were identified depending on the degree of maturation (Fig. 3). Squamous cell carcinoma was the most frequent tumor in our material. Metastatic adenocarcinoma often resembled the primary tumor. The tumor cells were often arranged in small clusters having indistinct cytoplasmic borders and round to ovoid nuclei (Fig. 4A). Further classification was often possible by paying attention to cell size and nuclear as well as cytoplasmic details. Endometrial carcinoma cells tended to be of small size and the chromatin pattern was coarse with multiple small nucleoli (Fig. 4B). Endocervical adenocarcinoma was often formed of tightly cohesive clusters of large cells having round to ovoid nuclei and cyanophilic cytoplasm (Fig. 5). Nuclear chromatin was often fine and there were usually single nucleoli. In some cases, however, the tumor cells were undifferentiated and the nature of the tumor was appreciated only after careful examination and comparison of both the initial biopsy and the aspiration material (Figs. 6, 7). In these cases, close attention to the clinical history and review of the previous material was an essential part of rendering an accurate diagnosis.

Seventeen patients had aspirations which were negative for metastatic carcinoma. Of these patients, seven had subsequent excision biopsies from the same site. Two of the patients demonstrated metastatic carcinoma; their aspiration biopsies were thus regarded as falsely negative. An additional three patients 


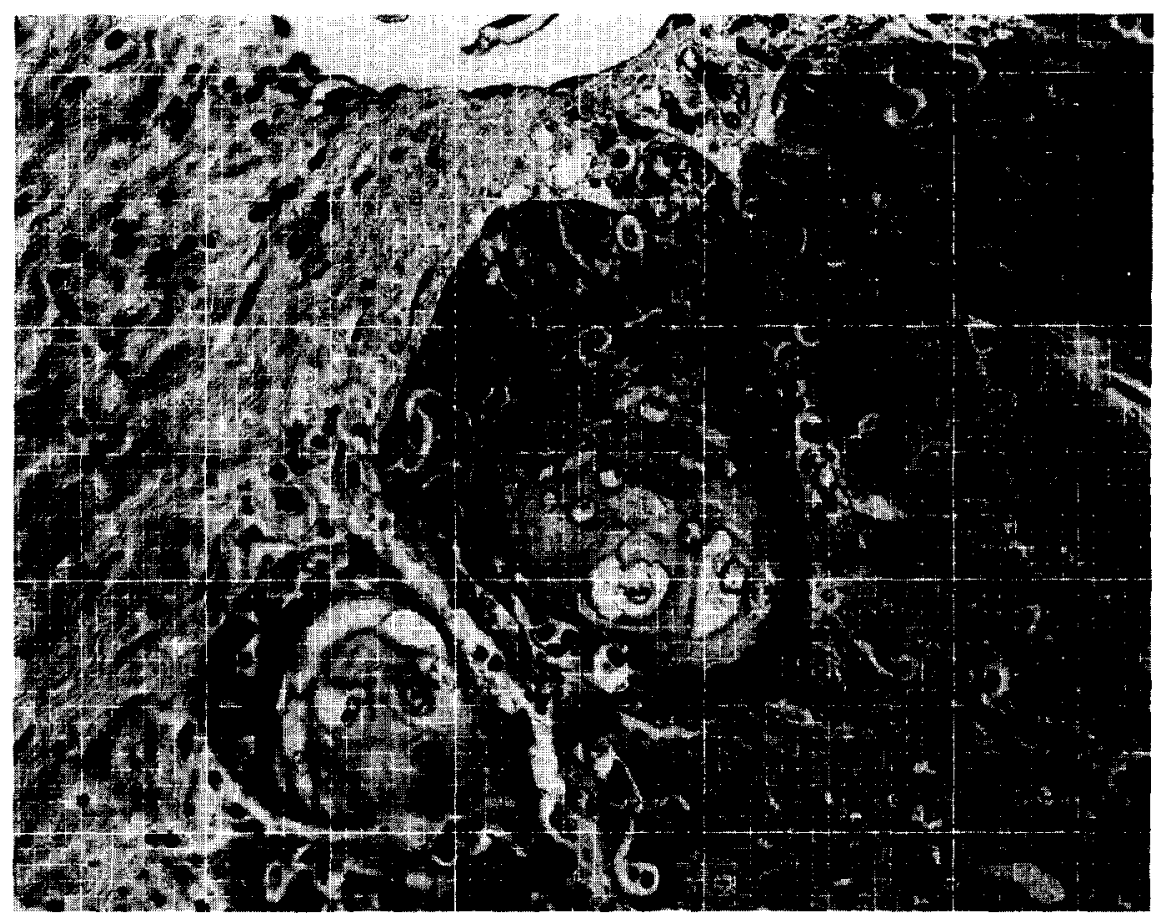

FIG. 3. Vaginal biopsy. Squamous cell carcinoma. Many tumor cell nuclei have coarse, irregular chromatin whereas other nuclei appear more condensed and hyperchromatic (hematoxylin and eosin, $125 \times)$.

developed recurrent tumor at other sites within 7 months of the aspiration biopsy. The remaining 12 patients $(25 \%)$ have no evidence of recurrence, from 1 month to 4 years following the aspiration biopsy.

Nine patients had unsatisfactory aspiration biopsies (Table 2). In each case, the aspirate contained excessive amounts of blood and very few lymphoid or atypical cells. Five of these patients underwent an excisional biopsy from the same site. In each case, metastatic carcinoma was demonstrated.

\section{DISCUSSION}

The use of the needle aspiration biopsy in order to document recurrent or metastatic carcinoma had been employed as early as 1921 [7], prior use of this technique having been for the diagnosis of infectious diseases [8]. However, as has been pointed out by Kline [9], Frable [10], and others, this technique had not enjoyed much popularity until only recently. Tumors from many different body sites (head and neck, breast, etc.) have been examined by this technique [11-13]. In recent years, relatively inaccessible tumors and metastatic foci have also been sampled. Zornoza and his colleagues [5] reported 17 patients with carcinoma of the cervix who underwent percutaneous abdominal biopsy of retroperitoneal and pelvic lymph nodes. No complications were encountered and a definite diagnosis was established by this method in $76 \%$ of the patients. 
A.

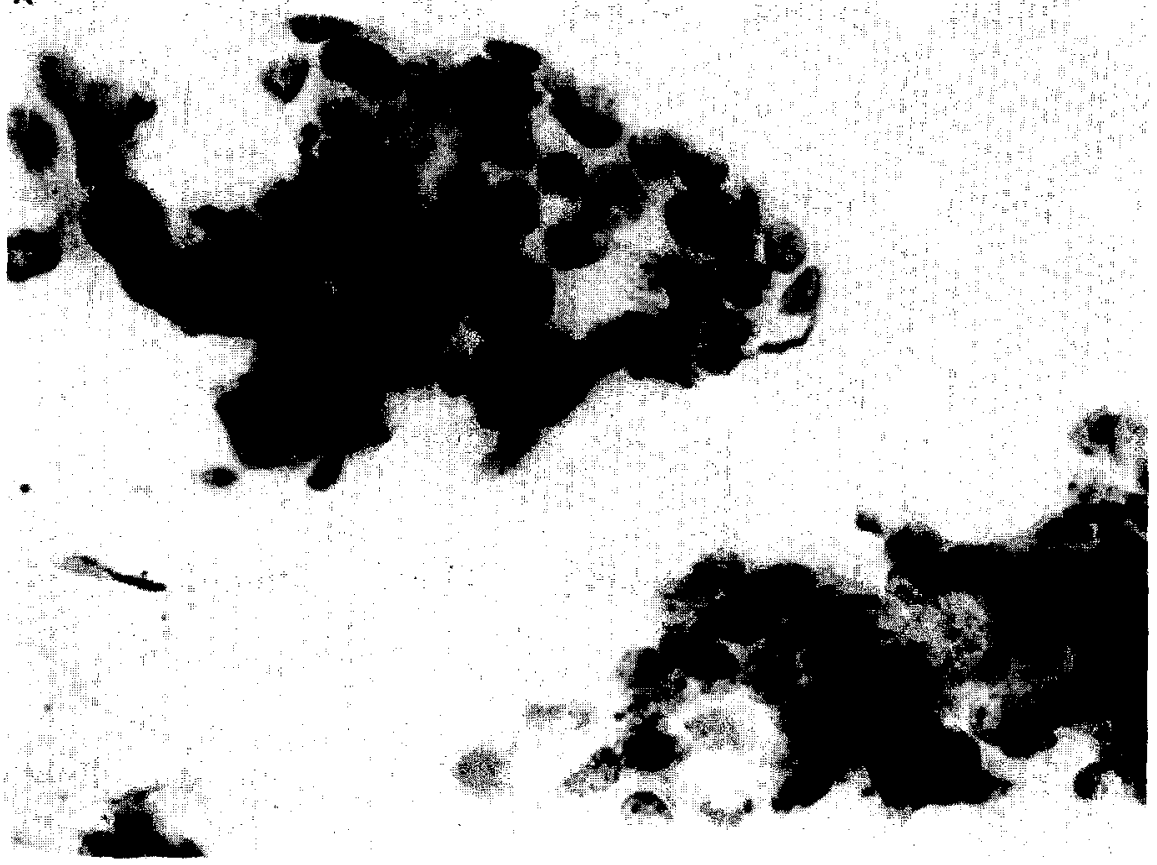

FIG. 4A. Endometrial adenocarcinoma. Small cluster of tumor cells with indistinct cytoplasmic borders and oval nuclei. Nucleoli may be conspicuous (Papanicolau stain, 250×).

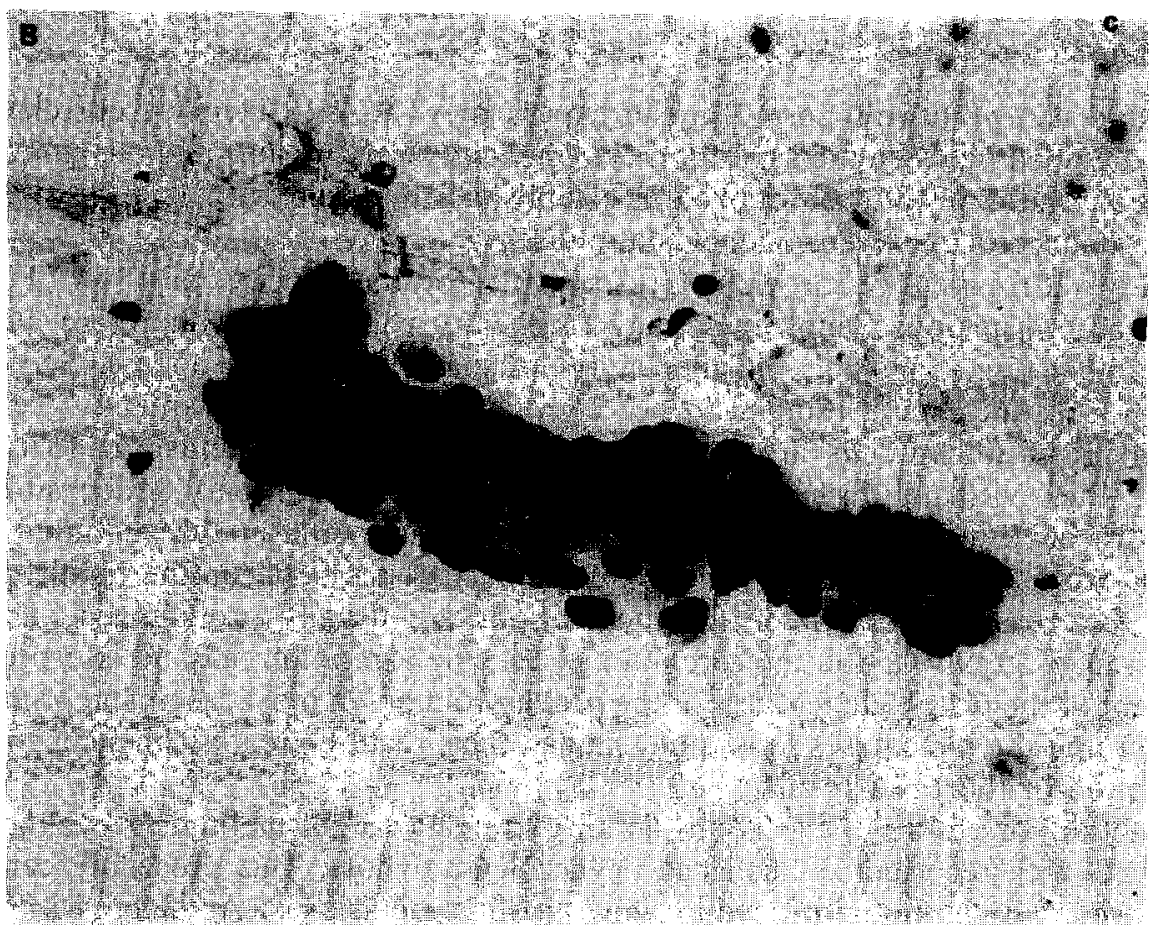

Fig. 4B. Endometrial adenocarcinoma. Note the coarse chromatin patterns and the multiple nucleoli (Papanicolau stain, $160 \times$ ). 


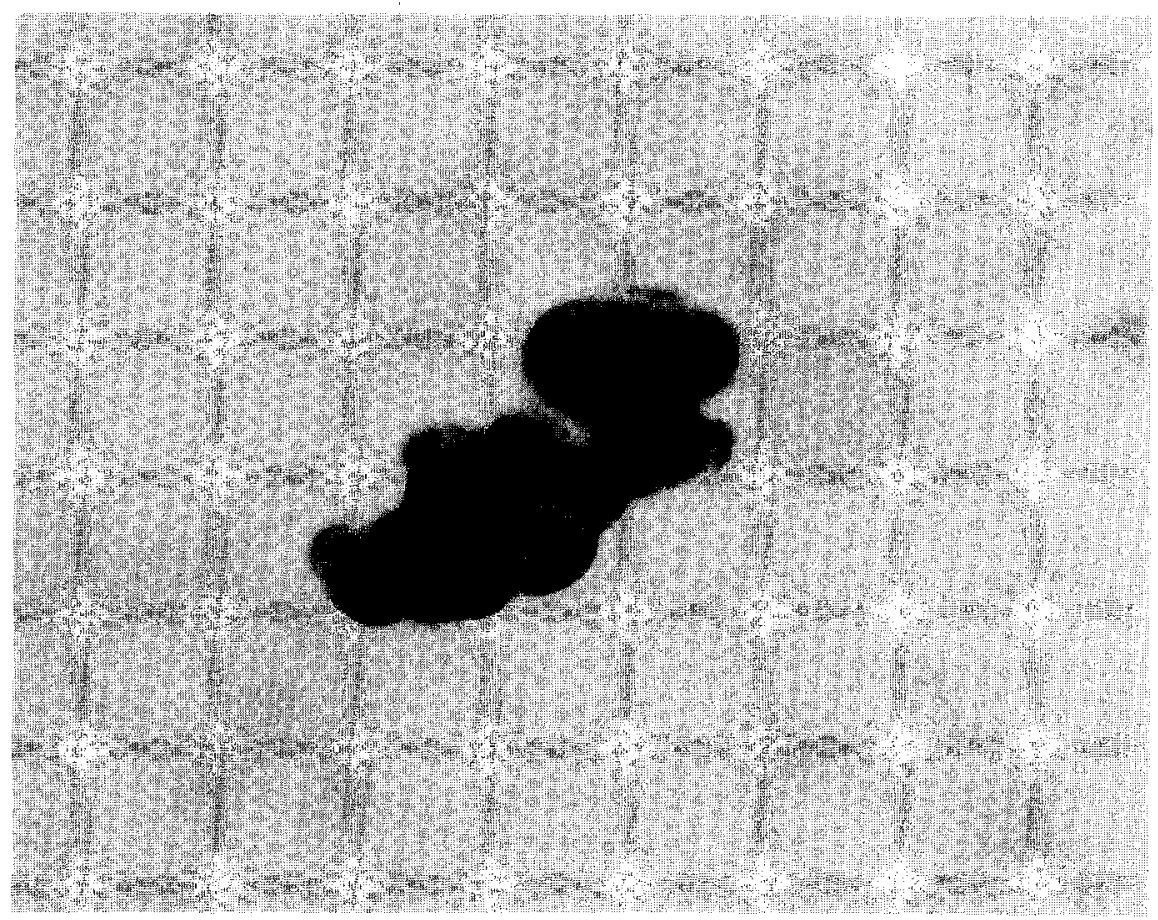

Fig. 5. Endocervical adcnocarcinoma. A tightly cohesive cluster of tumor cells. Note the nuclear molding by the peripheral tumor cells (Papanicolau stain, $500 \times$ ).

Nordquist et al. have reported similar experiences [14-16]. Excellent correlation was obtained between the aspiration cytology and biopsy results and the patient's clinical course. FNA was utilized in establishing the primary diagnosis as well as to document recurrent or metastatic disease.

Berg (17) gave several factors responsible for the success of FNA. First, clinically suspicious lymph nodes are frequently palpable and therefore easily accessible (e.g., inguinal, scalene, and supraclavicular lymph nodes). Second, since most metastatic tumors do not elicit a fibrous stromal response, greater numbers of tumor cells are more easily aspirated. Third, metastatic foci are usually less vascular, or have fewer blood vessels than the primary tumor; smears tend to have more tumor cells and less blood (carcinoma of the endometrium is an exception [17]). Fourth, the cytologic differences between the tumor cells and the normal lymph node cell populations are usually pronounced. These differences greatly aid in interpretation. Last, the aspiration may be interpreted in light of the histologic features of the primary tumor. In most cases, the primary tumor and the metastases look quite similar. This feature greatly enhances interpretation of the FNA results.

The authors found the FNA to be an extremely useful method of evaluating patients with recurrent or metastatic gynecologic tumors. This procedure can be performed as the initial procedure in evaluating metastases. As high as $24 \%$ of patients with stage I squamous cell carcinoma of the cervix and $20 \%$ of patients 


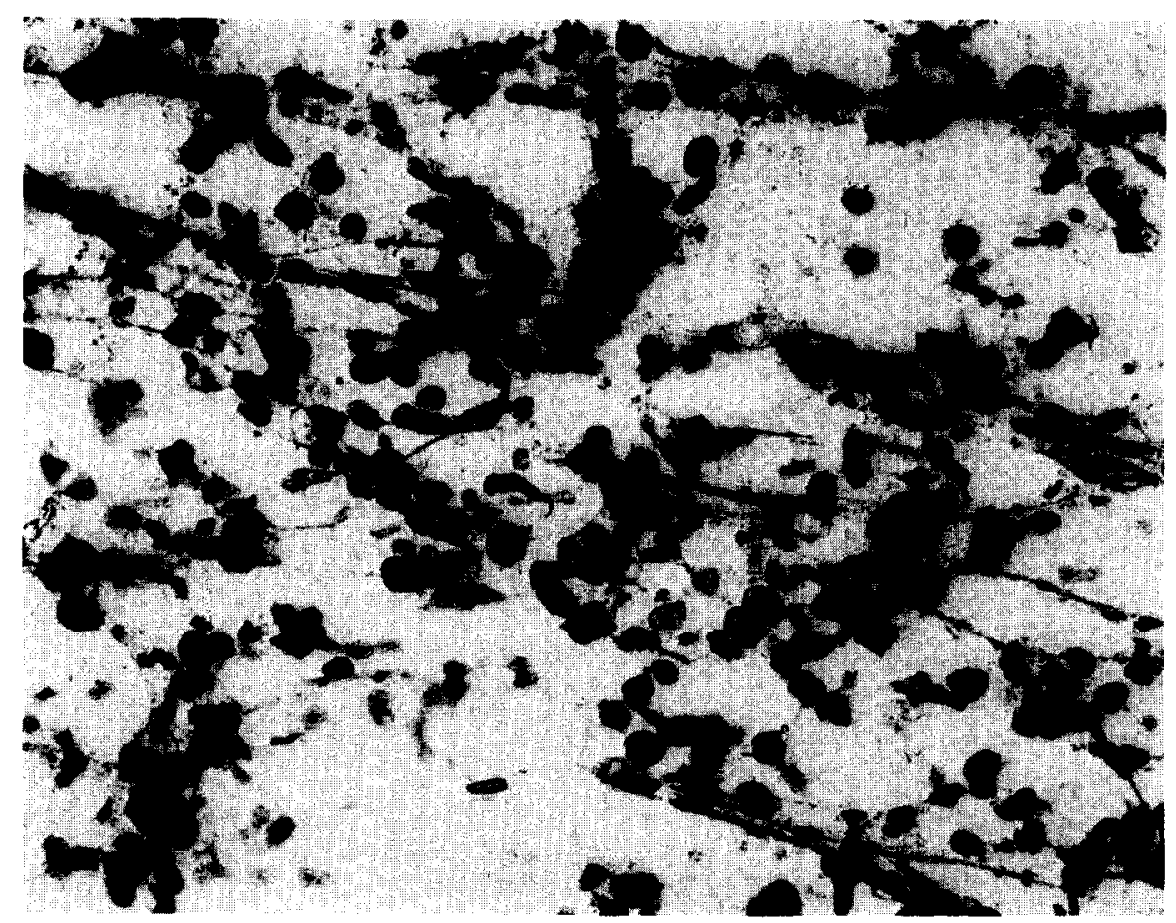

FIG. 6. Poorly differentiated carcinoma. The tumor cells exhibit only scant amounts of cytoplasm and large, hyperchromatic nuclei. The cytologic characteristics offer no clue as to the origin of the cells (Papanicolau stain, $160 \times$ ).

with stage I endometrial carcinoma may demonstrate pelvic and periaortic lymph node involvement [18]. Although the common sites of metastatic involvement are all within reach of the aspiration needle, detection of subclinical nodes remains problematic. Pelvic and paraaortic lymph nodes lie anterior to major abdominal vessels and are thus relatively accessible to an anterior transperitoneal biopsy approach. Computerized tomography, fluoroscopy, and ultrasound are sometimes employed to guide the biopsy.

The clinical impression of metastatic carcinoma was confirmed by FNA in $45 \%$ of the patients in this series. A total of $66 \%$ of patients had recurrent tumor, documented either by aspiration or open biopsy, or clinical course. Excellent correlation was observed in those patients who underwent concurrent excisional biopsies. There were no false-positive cases; two false-negative cases were recorded, results similar to those reported earlier [14-16]. One-third of the patients had no evidence of recurrent or metastatic disease. While some of these patients have had a relatively short follow-up observation, this finding is significant in terms of the exploratory surgery and/or therapy which these patients may otherwise have undergone.

The large proportion (21\%) of patients with unsatisfactory aspiration results was disappointing. Most of these patients had retroperitoneal lesions and had been evaluated during the early phase of our study. With experience and with 


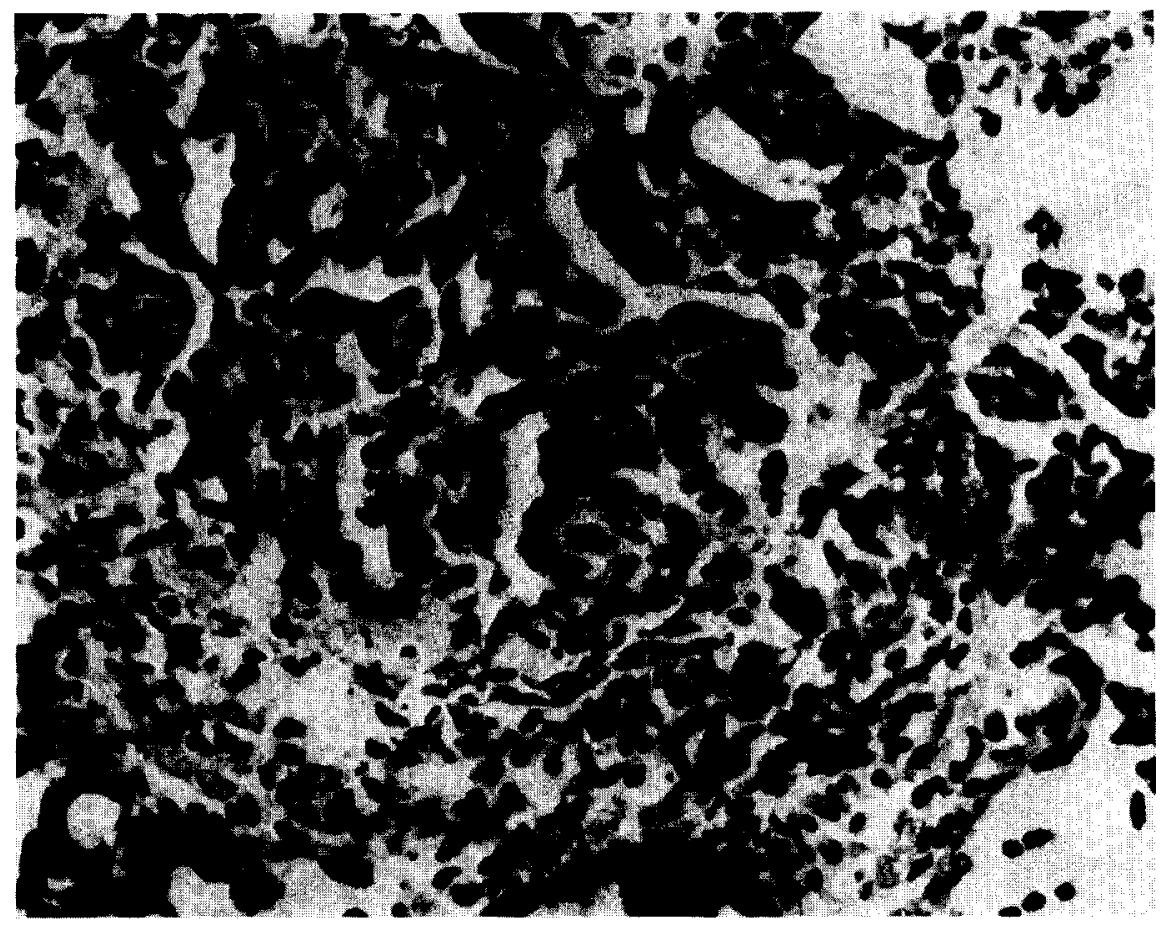

FIG. 7. Poorly differentiated endometrial adenocarcinoma. Irregular glands are formed by the tumor cells. The tumor cells are similar to those aspirated from a metastatic site, depicted in Fig. 6 (Hematoxylin and eosin, $160 \times$ ).

acceptance of the described technique, deep-seated tumors have been aspirated more successfully.

Complications, such as bowel perforation with subsequent peritonitis or intraabdominal hemorrhage, have not occurred. These potential complications, as well as the possibility of seeding tumor cells along the needle tract, have occurred only rarely in the larger reported series $[19,20]$.

FNA is easy to perform, enjoys a high degree of patient cooperation, and rapidly produces diagnostic information. Cytologic samples obtained in this manner may be accepted with confidence to diagnose malignant disease. "Negative" aspirates must be judged more cautiously, especially if the aspirate is scanty.

TABLE 2

Reliability of AspiRates

\begin{tabular}{lcccccc}
\hline & \multicolumn{3}{c}{ Sample } & & \multicolumn{2}{c}{ Sample } \\
\cline { 2 - 4 } \cline { 6 - 7 } & Number & Adequate & Inadequate & & "Negative" & Positive \\
\hline Inguinal & 33 & 29 & 4 & & 15 & 14 \\
Femoral & 1 & 1 & 0 & & 0 & 1 \\
Retroperitoneal & 9 & 4 & 5 & & 2 & 2 \\
Pelvic & 1 & 1 & 0 & & 0 & 1 \\
Supraclavicular & 4 & 4 & 0 & & 1 & 3 \\
\hline
\end{tabular}




\section{REFERENCES}

1. Chu, E. W., and Hoye, R. C. The clinician and the cytopathologist evaluate fine needle aspiration cytology, Acta Cytol. 17, 413-417 (1973).

2. Frable, W. J. Thin needle aspiration biopsy: A personal experience with 469 cases, Amer. $J$. Clin. Pathol. 65, 168-182 (1976).

3. Schour, L., and Chu, E. W. Fine needle aspiration in the management of patients with neoplastic disease, Acta Cytol. 18, 472-476 (1974).

4. Kline, T. A., Neal, H. S., and Holroyde, C. P. Needle aspiration biopsy: Diagnosis of subcutaneous nodules and lymph nodes, J. Amer. Med. Assoc. 235, 2848-2850 (1976).

5. Zornoza, J., Lukeman, J. M., Jing, B. S., Wharton, J. T., and Wallace, S. Percutaneous retroperitoneal lymph node biopsy in carcinoma of the cervix, Gynecol. Oncol. 5, 43-51 (1977).

6. Bonfiglio, T. A., MacIntosh, P. K., Patten, S. F., Cafer, D. J., Woodworth, F. E., and Kim, C. W. Fine needle aspiration cytopathology of retroperitoneal lymph nodes in the evaluation of metastatic disease, Acta Cytol. 23, 126-130 (1979).

7. Guthrie, C. G. Gland puncture as a diagnostic measure, Johns Hopkins Hosp. Bull. 32(366), 266-269 (1921).

8. Grieg, E. D. W., and Gray, A. C. H. Note on the lymphatic glands in sleeping sickness, Brit. Med. J. I, 1252 (1904).

9. Kline, T. S., and Hunter, N. S. Needle aspiration biopsy: A critical appraisal, J. Amer. Med. Assoc. 239, 36-39 (1978).

10. Frable, W. J., and Frable, M. S. Thin needle aspiration biopsy, Cancer 43, 1541-1548 (1979).

11. Godwin, J. T. Cytologic diagnosis of aspiration biopsies of solid or cystic tumors, Acta Cytol. 8, 206-214 (1964).

12. Stavric, G. D., Tevcev, D. T., Kaftandjiev, D. R., and Novak, J. J. Aspiration biopsy cytologic method in diagnosis of breast lesions: A critical review of 250 cases, Acta Cytol. 17, 188-189 (1973).

13. Zajicek. J. Aspiration biopsy cytology. Part I. Cytology of supradiaphragmatic organs, in Monographs in clinical cytology (G. L. Wied, Ed.), Karger, Basel, pp. 90-124 (1974).

14. Nordqvist, S. R. B., Sevin, B. U., Nadji, M., Greening, S. E., and Ng, A. B. P. Fine needle aspiration cytology in gynecologic oncology. 1. Diagnostic accuracy, Obstet. Gynecol. 54, 719-724 (1974).

15. Sevin, B. U., Greening, S. E., Nadji, M., Ng, A. B. P., Averette, H. E., and Nordqvist, S. R. B. Fine needle aspiration cytology in gynecologic oncology. I. Clinical aspects, Acta Cytol. 23, 277-281 (1979).

16. Nadji, M., Greening, S. E., Sevin, B. U., Averette, H. E., Nordqvist, S. R. B., and Ng, A. B. P. Fine needle aspiration cytology in gynecologic oncology. II. Morphologic aspects, Acta Cytol. 23, 380-388 (1979).

17. Koss, L. G. Diagnostic cytology and its histopathologic bases, Lippincott, Philadelphia, pp. 311-321 (1961).

18. Gerteis, W. The frequency of metastases in carcinoma of the cervix and the corpus, in Progress in Lymphology, Proceedings of the International Symposium on Lymphology (A. Ruttimann, Ed.), Verlag, Stuttgart, pp. 209-211 (1966).

19. Zajicek, S. Aspiration biopsy cytology. Part I. Cytology of supradiaphragmatic organs, in Monographs in clinical cytology (G. L. Wied, Ed.), Karger, Basel, pp. 20-24 (1974).

20. Soderstrom, N. Fine needle aspiration biopsy, Grune \& Stratton, New York, pp. 19-23 (1966). 